\title{
Dynamic Simulation of AC Contactor Operating Mechanism
}

\author{
Zhang Yufeng ${ }^{*}$ and Li Lufeng
}

Jiangsu Institute of Architectural Technology, Xuzhou, 221116, China

\begin{abstract}
Unigraphics NX (UG NX) software is mechanical engineering aided design system development America UGS a set of CAD / CAM / CAE in one. UG originated in USA McDonnell Douglas Aircraft Company, later merged in 1991 into the world's largest software company -- EDS. Widely used in electronics, aviation, automobile, household appliances, toys and other industries. By modeling the characteristics of UG based entity, has the dimension driven editing and unified database. The core of parasolid provides powerful modeling software and seamless data conversion ability, digital model of UG established capable of data conversion in a variety of software, and provides convenience for data exchange.
\end{abstract}

Keywords: CAD/CAE/CAM software, CJX2-40 type AC contactor, dynamic simulation

\section{ESTABLISHING THE VIRTUAL PROTOTYPING OF CONTACTOR MECHANICAL SYSTEM}

The modeling features of UG: UG provides a very flexible composite modeling methods, it realizes the association and shared between all relevant and digital entity modeling data for users to edit graphics is very convenient. Such as solid modeling (Solid), surface modeling (Surface), the wire frame modeling (Wireframe), feature modeling and realistic photographic powerful rendering [1], animation and rapid prototyping tool based on. The user can mix various modeling method according to actual needs, fully display its superiority modeling, UG users can quickly and accurately the tolerance feature will feature information of tolerance and geometric objects associated, so that you can on the assembly model analysis.

UG software in the design of software has a great advantage in the aspect of modeling, management and development. Through the software understanding, general characteristics are: desktop style is very simple; the main model can conveniently inquire into the parameter expression; tree management style history, can easily query to the entire modeling step; a strong hint function for modeling process, every step has clear indication; software has development, provides two times the development of means, provides convenience to meet different needs of enterprises [2].

Unigraphics works in the product development the most competitive victory in the MACD industry, compared the characters and functions of UG, has many unique features, such as: Unigraphics provides a powerful programming framework, so that customers and suppliers of software applications can be developed with UG very good integration and complete relevant, personalized the program can continue to add users. In the machinery industry, the most closely to CAD/CAM/CAE integrated with PDM, the formation of the whole design, analysis, processing, management integration of a high level of software. In the extended enterprise customers the meaning of the data can be converted to each other, even including those input data is the problem of the high rate of success of intelligent conversion etc.

UG software into China for more than 20 years, has been widely recognized by Chinese enterprises, has become one of the main use of China's industrial sector, large-scale $\mathrm{CAD} / \mathrm{CAE} / \mathrm{CAM}$ software, the topic selected the software as modeling software.

\subsection{The Generation of 3D Modeling and Virtual Prototype}

For the simulation of virtual prototype in ADAMS analysis, 3D modeling first machinery for AC contactor with modeling software, and then to the specific file format output, and then through the interface module of ADAMS and CAD, into ADAMS simulation of kinematics and dynamics simulation. The establishment of model is a very important step dynamic simulation, so to carry out dynamic simulation to first ADAMS model of 3D modeling into use can be. The 3D modeling function of UG based on the good [3], according to the structure and material properties of $\mathrm{AC}$ electromagnetic contactor, the completion of the final model in UG is divided into two steps: establishing the model of parts and the whole assembly.

Needed to establish the CJX2-40 type AC contactor model components including: dynamic and static contact, an armature, a static iron core, a spring support, shading, contact support, small contact support and base.

\subsection{Parts Modeling}

Modeling can choose 3D drawing directly according to the structure characteristics of components, can also choose to draw 2D sketch and then by drawing some simple operations such as 3D solid model. In this paper, cross using two kinds of modeling methods, the steps can be summarized as: 
(1) select a reference drawing the contour of the part drawing, sketch, attention must be paid to this time, should be timely finish sketch on the amount of value constraints, can not be over constrained or under constraint.

(2) stretching or rotating operation, setting parameter bias thickness, get the entity.

(3) processing, drilling and other work in the entity, get the model.
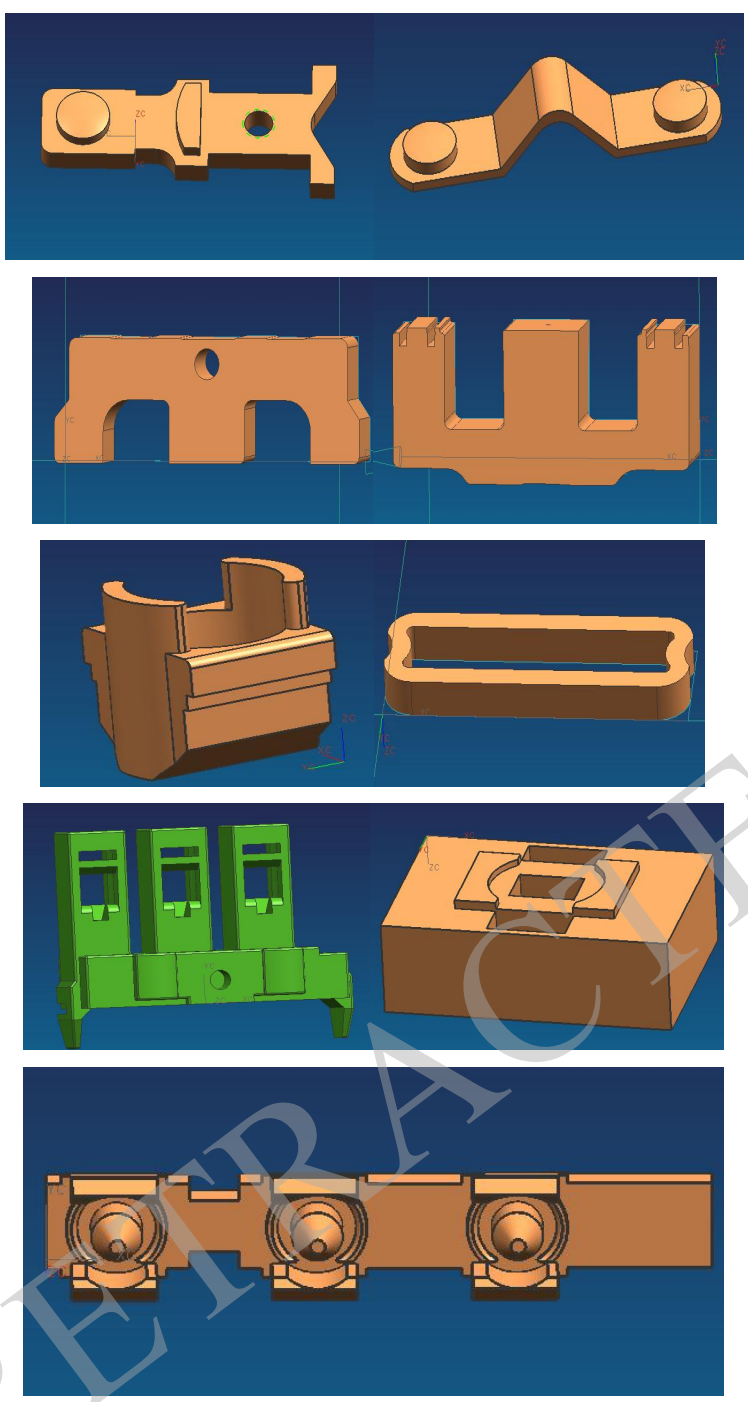

Fig. (1). 3D model for each component of contactor.

Note: the right from the left in the figure, from top to bottom in turn. As a static contact, a moving contact, a static iron core, an armature, a spring support, shading, contact support, a base and a small contact support.

\subsubsection{The Whole Assembly}

Assembly is the process when the parts according to the actual structure of contactor together [4]. In each direction, it requires the parts in the assembly space must have the location constraint, constraint completely after the position

of a component without any rotation, drag or move between. Among them, the positioning constraints is the key position of each part of the structure of its requirements specified contactor very familiar [5-7].

For example, in the assembly process, cooperation between the contactor dynamic contact bridge with a spring support and a contact support, if the assembly is not good, directly affect the motion simulation process. In fact, the moving contact bridge will occur in small offset super stage, is not completely fixed, between the moving contact bridge and contact support is tangent lines and surfaces, and the spring support is also tangent line and plane.

Visible every step positioning constraints are very important, so the assembly is a time-consuming process, it is a need of patience and careful work. After assembly, 3D model is shown in UG CJX2-40 type AC contactor in Fig. (2).

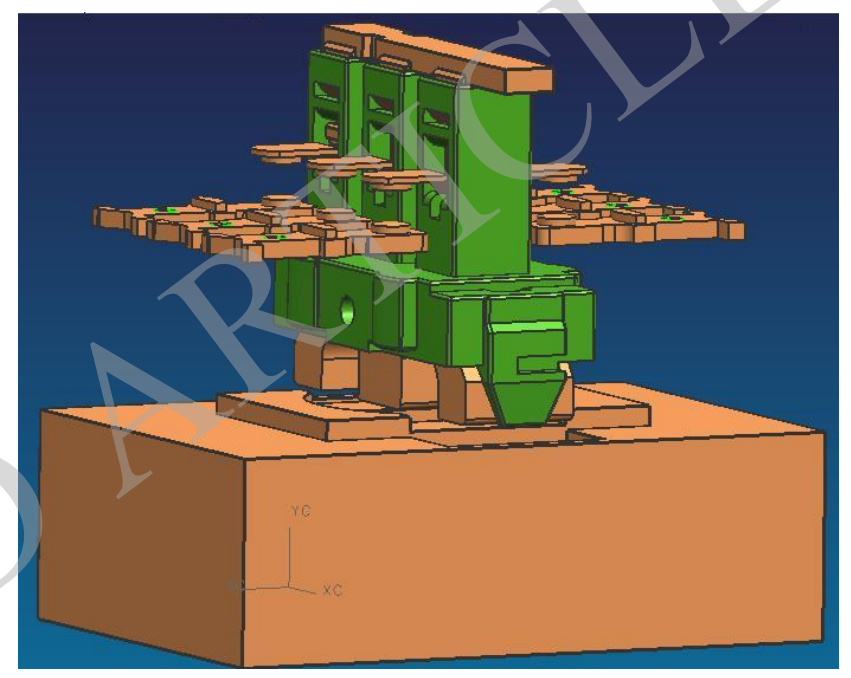

Fig. (2). 3D model of CJX2-40 AC contactor in UG.

\subsection{The Dynamic Differential Equation of Mechanical System of AC Contactor}

In general, by nonlinear differential equations to represent the dynamic process of electric appliance is switched on [8].

The coil of the electromagnet loop equation:

$u=i R+\frac{d \psi}{d t}$

Displacement equation of motion for the electrical part:

$F=m \frac{d^{2} x}{d t^{2}}+F_{f}(x)+F_{f}\left(\frac{d x}{d t}\right)$

Electromagnet suction equation:

$F=f(i, x)$

The above equations with analytic method is impossible to solve analytically rigorous. With the development of modern electronic computer, a variety of simulation software greatly reduces the heavy workload of the previous calculation, and improve the calculation accuracy. 


\section{DYNAMIC SIMULATION OF MECHANICAL SYSTEM}

\subsection{Introduces ADAMS Software}

ADAMS, namely the automatic dynamic analysis of mechanical system (Automatic Dynamic Analysis of Mechanical Systems), software is America company MDI (Mechanical Dynamics Inc.) the development of virtual prototype analysis software. In today's world with the virtual prototype technology most widely application software for ADAMS, is Ji Jianmo, solving, mechanical system simulation visualization technology in one of the analysis software, the software can be very convenient to establish the mechanical system simulation model, analysis the statics, kinematics and dynamics, output displacement, velocity, acceleration and reaction force, can also be 3D modeling software such as PRO/E [39], UG, SlidWorks and other powerful modeling function of the application of machinery, and then to the specific file format output, and then through the interface module of ADAMS and CAD, such as IGES, STEP, ADMAS/Exchange support DXF/DWG, Parasolid and other graphics interchange format into ADAMS simulation of kinematics and dynamics simulation, more expanded the scope of its application.

At present, ADAMS has been hundreds of main manufacturers around the world by all walks of life. ADAMS software uses an interactive graphical environment and parts library, beam, stress, mechanical system to create fully parametric geometric model, Lagrange equation method of multi rigid body system dynamics theory is used in the solver, establish the system dynamic equation, the virtual machine system statics, kinematics and dynamics analysis, the output displacement, velocity, acceleration and reaction force. The ADAMS software simulation can be used to predict the performance of mechanical system, range of motion, collision detection, peak load and input load finite element calculation etc..

Users of the ADAMS software, multi-body dynamics virtual prototype model can automatically generate arbitrary machine - electric - hydraulic - integration, complex system, can provide the calculation results from the product conceptual design, scheme demonstration, detailed design to modify the product scheme, optimization, experiment planning and fault diagnosis of the stage, full range, high simulation precision for the user. So as to shorten product development cycle, reduce development costs, improve product quality and competitiveness of purpose. Because ADAMS has the simulation function of general, accurate, convenient and friendly user interface and powerful graphical animation display capability of large companies in the software has been in much of the world was successful used [9].

ADAMS is the application of the virtual prototype analysis software, users can conveniently carry on statics of the virtual machine system using the software, the kinematics and dynamics analysis. On the other hand, it is the analysis of virtual prototype development tool, the open structure of the program and a variety of interface, can become a special industry users two development tools platform analysis of special type of virtual prototype.
Use ADAMS to build virtual prototype is very easy, by interactive graphical user interfaces and a rich library of simulation unit, the user can build the model of the system fast. ADMAS and advanced CAD software (UG, CATIA, Pro/E) and CAE software (ANSYS) can exchange files by computer graphics exchange in order to maintain the consistency of data. The ADAMS software support concurrent engineering environment, save a lot of time and funds, establishing parameter by ADAMS software model can be used to design research, analysis of experimental design and optimization, provides an efficient tool for system parameterization [10].

ADAMS software is composed of basic module expansion module, interface module, professional field module and 5 types of modules toolbox. The core module of ADAMS/View will be convenient icon operation menu, click of the mouse from operation and interactive graphics modeling, simulation, animation display, optimization design, $\mathrm{X}-\mathrm{Y}$ curve analysis and the result of data processing, printing and other functions are integrated together, provides pretreatment function analysis of a basic operation dialogue environment and virtual prototype for the user.

Users can not only use the universal module to simulate the mechanical system, but also can carry on Modeling and simulation analysis of fast and effective use of special module to solve the problem of application domain specific industry.

\subsection{The Design Process}

Based on the stiffness and strength of CJX2-40 type AC contactor material, and each component size requirements, combined with the establishment of virtual prototype of $\mathrm{AC}$ contactor using UG NX and ADAMS.

Concrete steps to establish the three-dimensional model of AC contactor is:

Step 1, 3D solid model was established by UG components; model, try to ignore the effect of small parts to simplify model, because in ADAMS the simulation in this paper, the main research is $\mathrm{AC}$ electromagnetic contactor main contact system and electromagnetic system, mainly including: node structure is a small contact support, a spring support, the moving contact bridge, static main contact, a contact support (support), spring, dynamic and static iron core, a base [11]. Therefore, some parts (such as shell, auxiliary contact etc.) can be omitted, thus reducing the complex degree.

Step 2, the completion of assembly and simple constraints of the overall model in UG; due to the designated AC contactor for accurate modeling is critical to the simulation research, and therefore require positioning must be accurate.

Step 3, put the model into ADAMS, and add the characteristics and residual complex constraint, force; consider using the combination of UG and ADAMS software, it will bring some inconvenience, so positioning, work is not only in UG, but also included in ADAMS, and it is closely related to the. For example, in the initial modeling structure size is incorrect or not fully consider, it will directly affect the establishment and Simulation prototype into 
ADAMS, then can return to re positioning the UG environment, and before the ADAMS work will become useless.

The modeling process also need to pay attention to units. Because of the need to combine with ADAMS, "mm, kg, N, the business unit $\mathrm{C}^{\prime \prime}$ is an ideal choice for. So will the default unit is set to "mm, $\mathrm{kg}, \mathrm{N}, \mathrm{C}$, this can save a lot of trouble in the process of modeling. Therefore, the positioning of work must be done when modeling, which will greatly reduce the workload.

Step 4, detailed simulation;

Step 5, verify whether results conform, if met the simulation ends, if do not meet, will need to return to check the front steps to modify, and then simulation.

Should pay attention to in the process of modeling is to model the accurate positioning and correct. The 3D model as shown in Fig. (3).

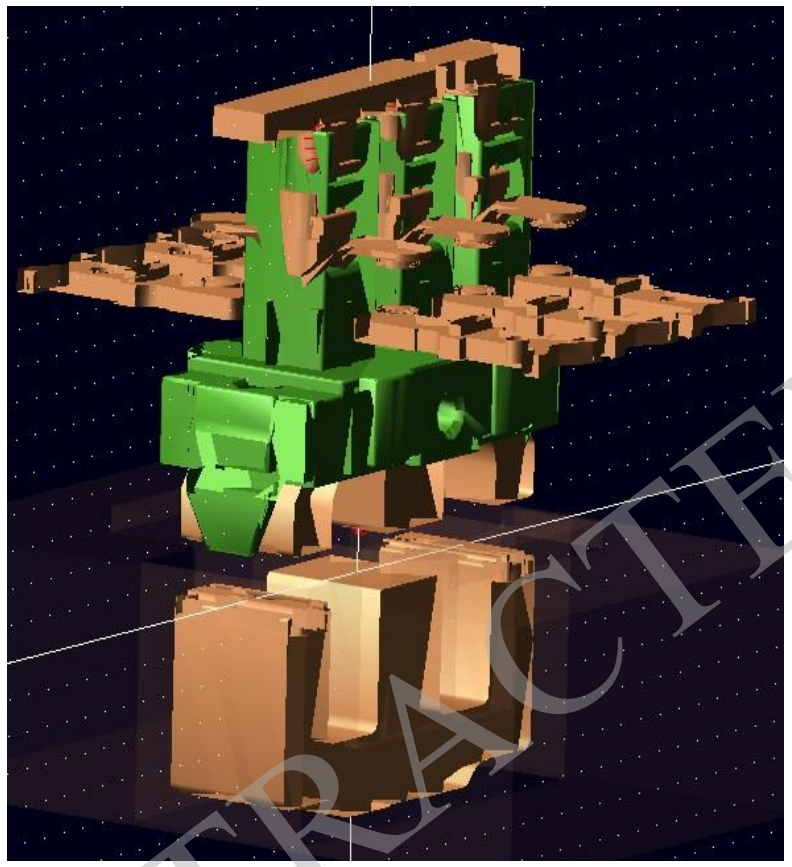

Fig. (3). Model of virtual prototype.

Because ADAMS is good for the parasolid file format identification, after importing file will correctly identify each component and related information, therefore, the complete assembly in the UG after should be saved as the parasolid file name extension, research on Simulation of the motion characteristic of contactor to easily import in ADAMS environment [12].

But this after import is not completed the task, because the implementation model in UG ADAMS environment and the different functions which need constraints are also different, so the introduction of new environment, to once again to add constraints model, and it is an important link. This still requires us to understand the structure and working principle of AC electromagnetic contactor, with at the same time to become familiar with the various body parts of the contactor is not to be ignored.

First set the working environment, working grid (Working Grid) mesh size dialog (size) of $\mathrm{X}, \mathrm{y}$ is set to
$200 \mathrm{~mm}$, the spacing (spacing) of $\mathrm{X}, \mathrm{y}$ is set to $5 \mathrm{~mm}$, according to the requirements of contactor work, will the time unit is set to MS, to facilitate the observation of the dynamic process of the contactor.

Secondly, create motion pair (Joints), the simulation model correctness of kinematic pairs is correct or not play a decisive role in. To determine the connection between objects and how objects in relative motion, constraints imposed on the components. This paper will not consider the cushion under static iron core, therefore between the static iron core and the earth add fixed side, between the static contact with the earth, between the bracket and the armature also add a fixed vice.

Furthermore, a flexible connection between the spring support and small contact support, the armature and the static iron core is created between the spring. The dynamic and static contact between contact and contact force, creating movement between the core.

Finally, the contact force between the core set of static and dynamic, respectively, the establishment of a Marker point in the armature and the static iron core, the creation of the SPLINE 1 in the Adams/View Build in the menu bar of Data Elements, namely the suction $Y$ changes with the air gap $\mathrm{X}$ form. The suction characteristics of these data sources in CJX2-40 AC contactor electromagnetic calculated by ansoft. According to the Akima Fitting Method (AKISPL) format requirements established under the function Function contact force in the contact force of dynamic and static iron core of the dialog box, AKISPL (DY (MARKER_241, MARKER 242), 0, SPLINE 1), where MARKER $2 \overline{4} 1$ is the armature from the point MARKER_242 is a point on the static iron core.

\subsection{Dynamic Simulation of Mechanical System Under Sinusoidal Excitation}

In the third chapter, ADAMS combined with Maxwell 3D simulation results of the contactor electromagnetic system and 3D model of the first section of this chapter established based on UG, the dynamic simulation analysis of contact system of this paper of CJX2-40 type AC electromagnetic contactor, mainly including the movement of a movable contact, and the contact spring tower spring. Simulation interface as shown in Fig. (5).

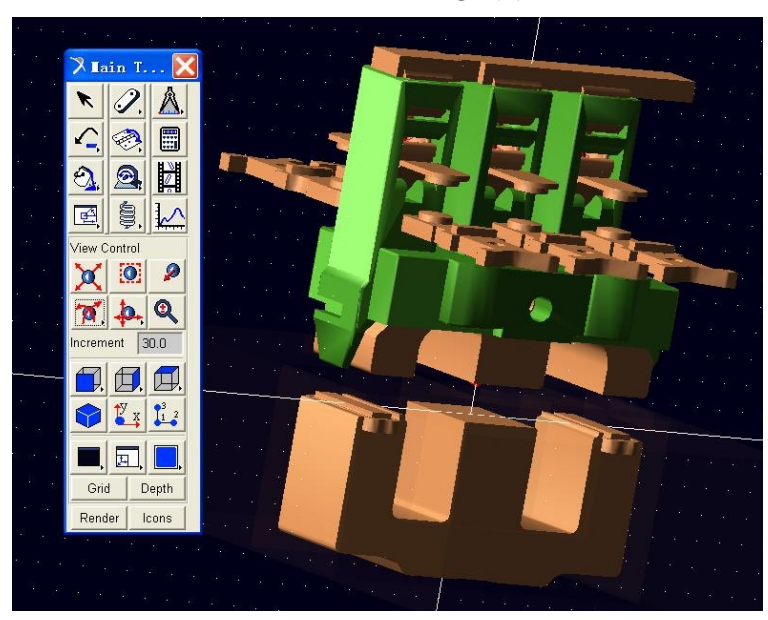

Fig. (5). Simulation interface. 

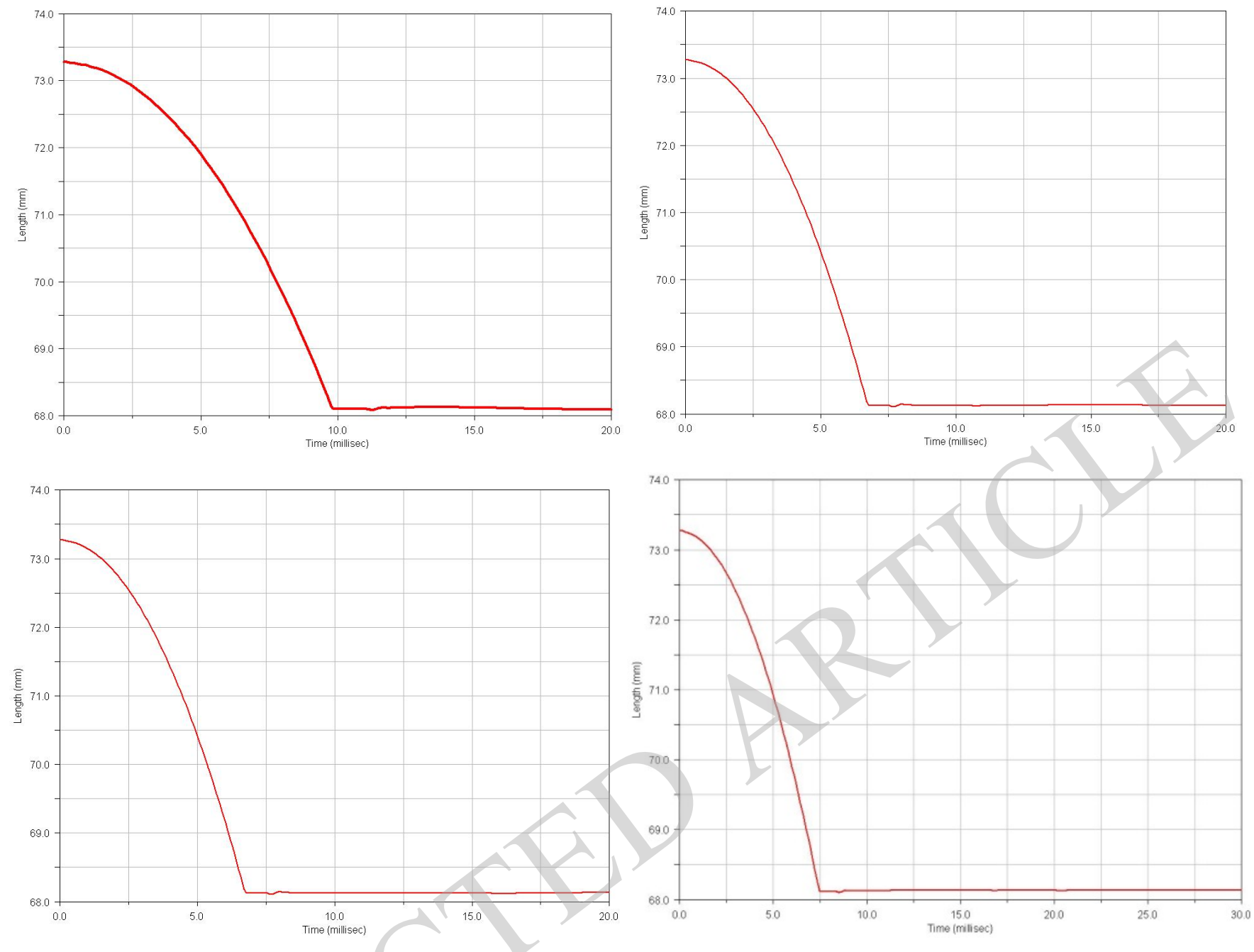

Fig. (6). The position of moving-contact.

The following from left to right, from top to bottom are given under sinusoidal excitation, closing phase angle for the dynamic characteristic curves of 0 degrees, 45 degrees, 60 degrees, 90 degrees calculated1.

According to the working principle of CJX2-40 type AC electromagnetic contactor, combined with the Fig. (6) motion displacement contact available motion distance contact is opening dimension, this paper CJX2-40 type AC electromagnetic contactor open distance is $5.2 \mathrm{~mm}$, and the simulation results show that the dynamic contact displacement and actual displacement, and dynamic and static contact closure after almost invariant, illustrate the contactor is attracted reliably. Furthermore, different closing phase angle makes the dynamic and static contact to complete closure action time is different [13].

In Fig. (7) it is clear that the moving contact in different closing phase angle, the armature generate electromagnetic suction different, so as to drive the contacts movement speed is different.

Since the tower spring in the armature and the static iron core, provides a part of reaction force for the contactor, have certain relation to the characteristics of deformation and contactor action.

According to Figs. (9, 10) column spring force and displacement variation of deformation can be obtained, tower spring between the armature and a yoke distance is $7.1 \mathrm{~mm}$, which is consistent with the research object of real value in the. At the same time also can draw different tower spring, closing phase specific stress are different.

Because the three main contact spring force are basic and same, this paper chooses one of the phases as the research object. The main contact spring provides another part of the reaction, the forces which can reflect the contactor suction with anti force.

In Figs. $(11,12)$ may, different contact spring with the closing phase angle, the stress situation is different, and in the closing phase angle of 0 degrees, the contact spring compression appear small rebound, is likely to affect the normal work of the contactor.

Displacement variation of the contact spring is movable contact the main reasons of ultra distance, this paper selected the contactor super path is $1.9 \mathrm{~mm}$, the figure shows the simulation results tally with the actual.

In summary, the sinusoidal excitation different closing phase angle, the situation is basically stable work contactor. 

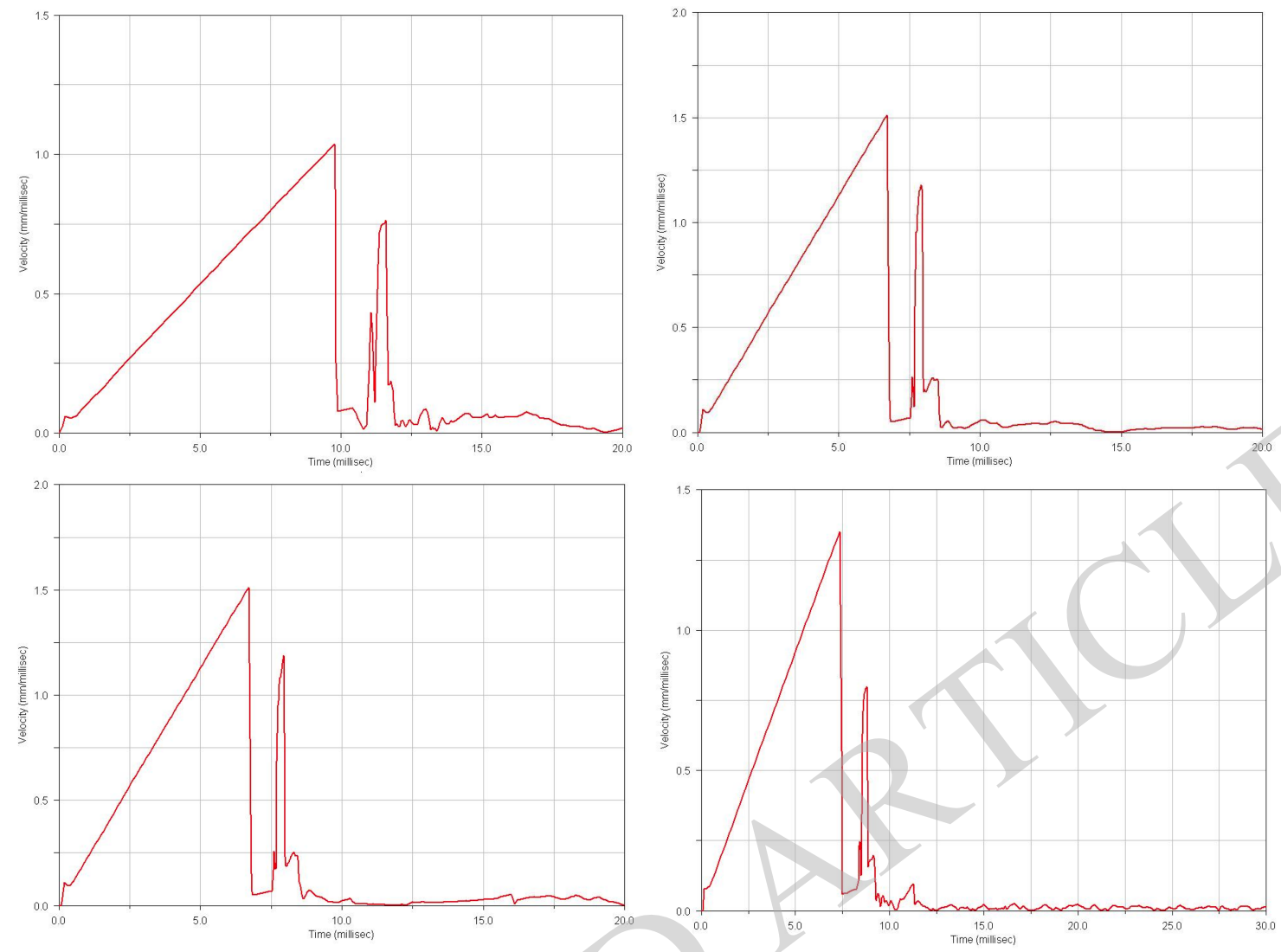

Fig. (7). The speed of moving-contact.
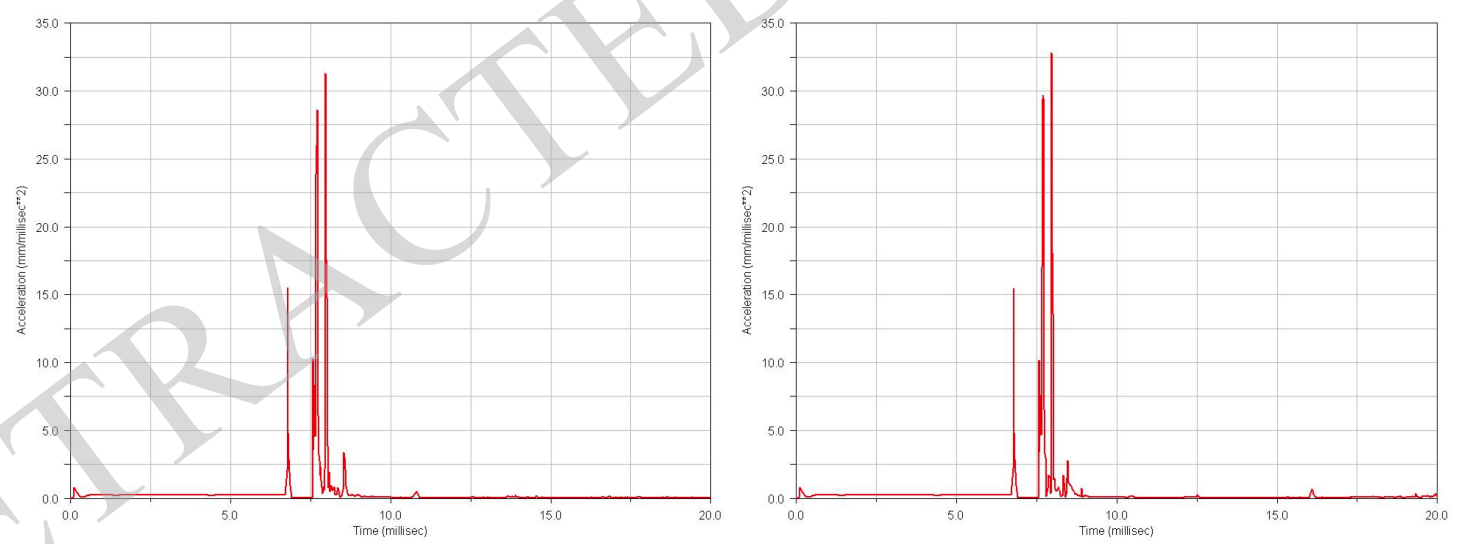

Fig. (8). Acceleration of moving-contact
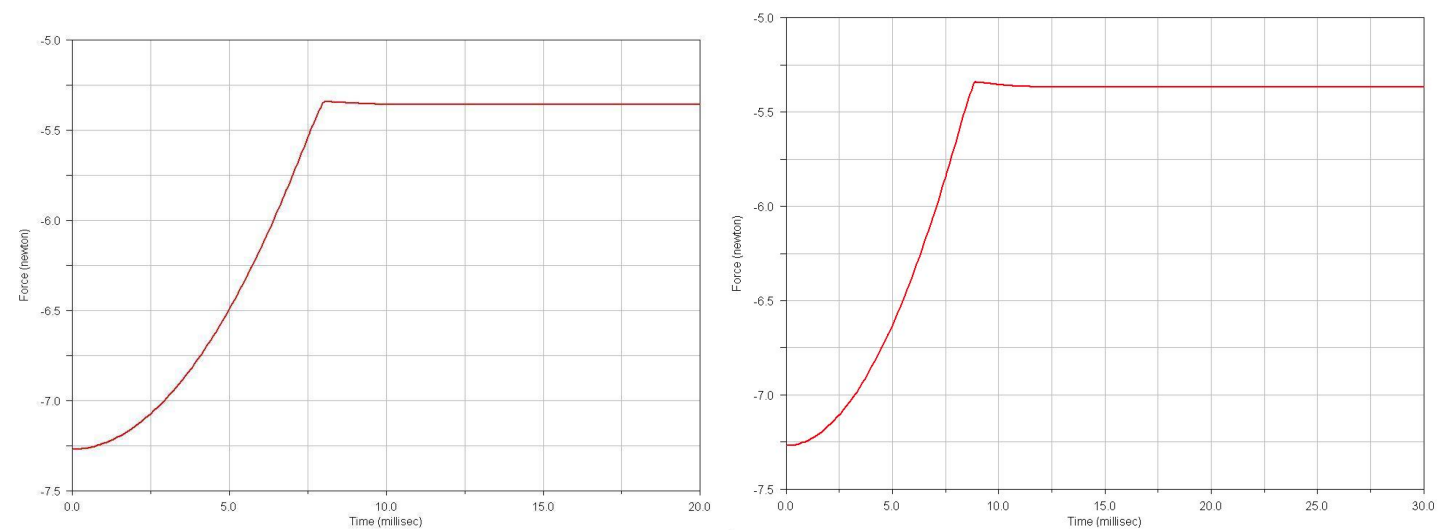

Fig. (9). Force of spring. 

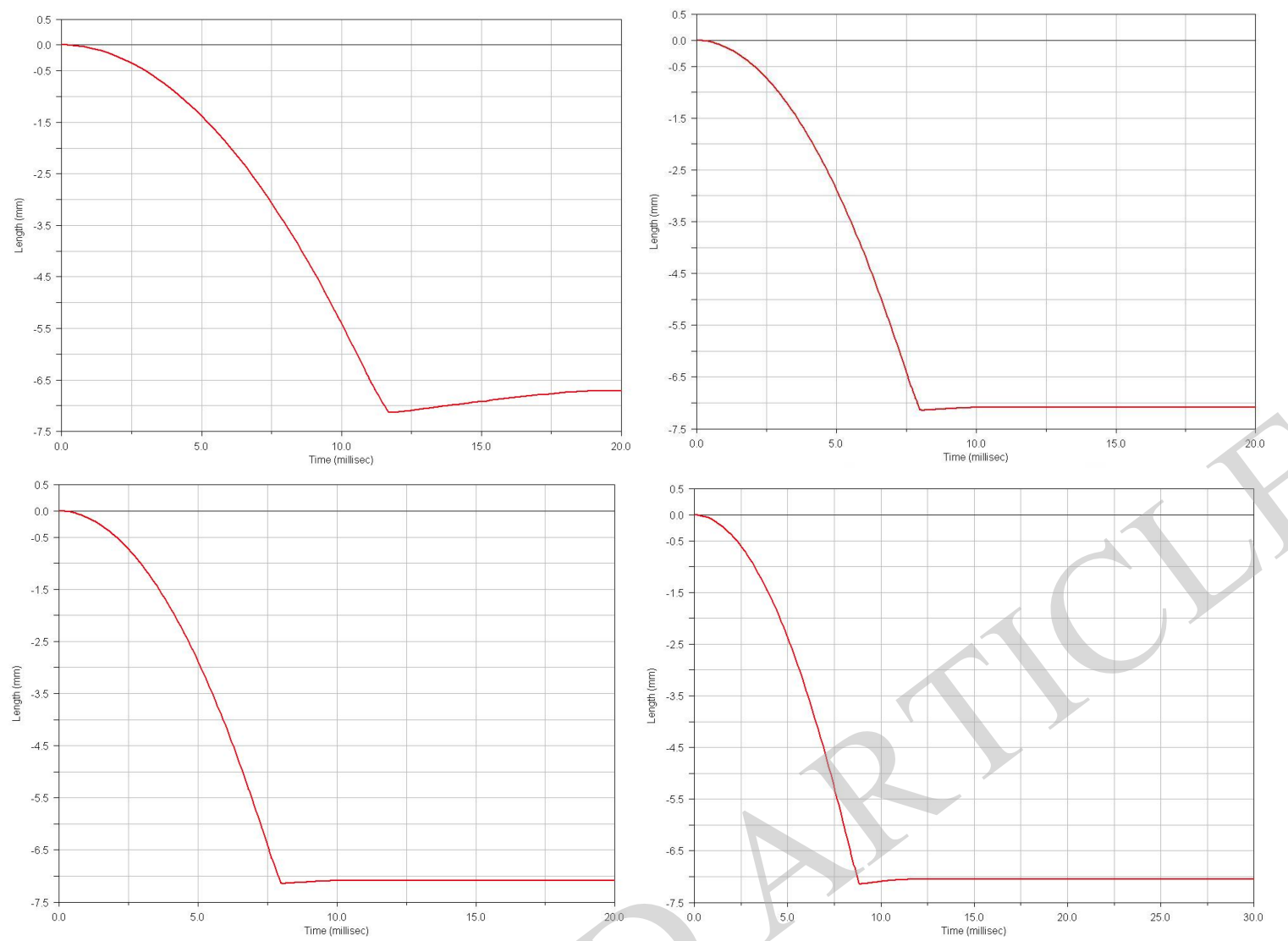

Fig. (10). Position of spring.
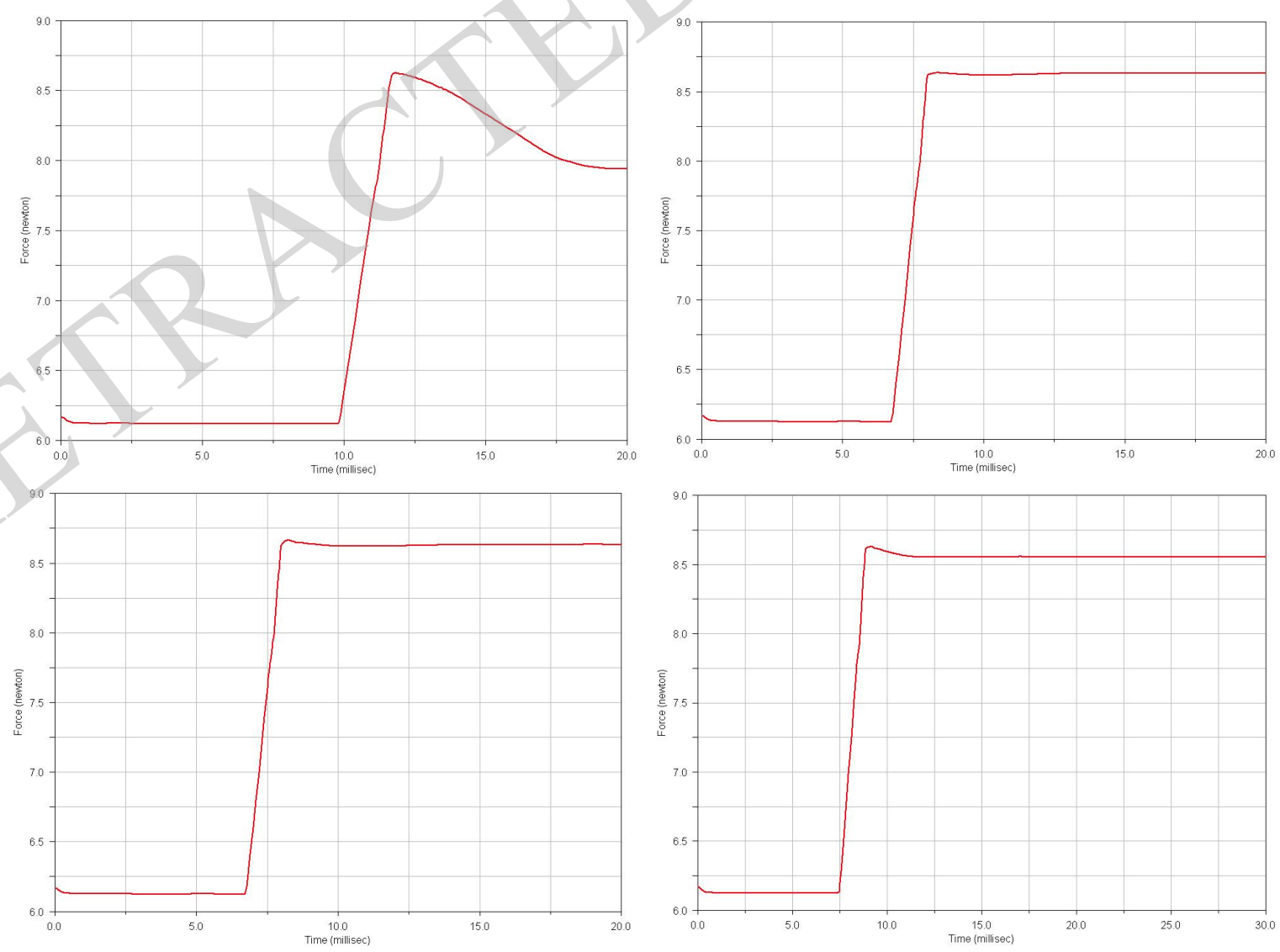

Fig. (11). Force of contact spring. 

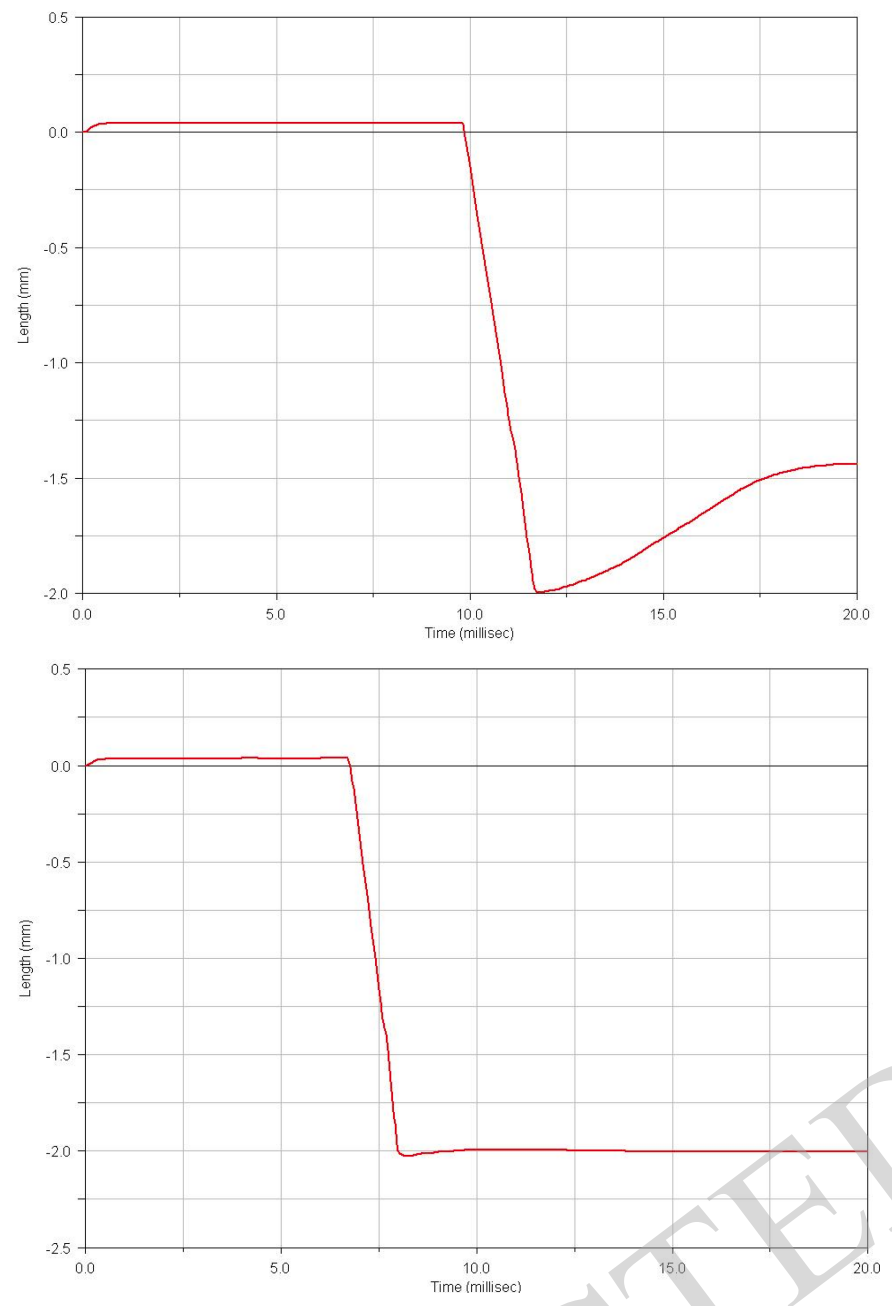

Fig. (12). Position of contact spring.

\section{COMPARISON OF THE SIMULATION RESULTS}

Through the above analysis, in different closing phase angle drills dynamic mechanism dynamic characteristics. Including:

\subsection{Time Characteristic}

Change in movement time as a function of the applied excitation is different. In a phase will appear under the minimum speed, at this time the longest time for action. The average is less than the velocity under harmonic excitation sine excitation speed, namely power containing harmonic component of the excitation source, movement time was longer than the sine excitation source.

\subsection{Speed Characteristics}

The moving contact terminal velocity variation is complex, and it is through the observation of multi peak function, associated with the closing phase angle. Under different excitation, the maximum closing phase angle of different terminal velocities and minimum occurs moments are also different.
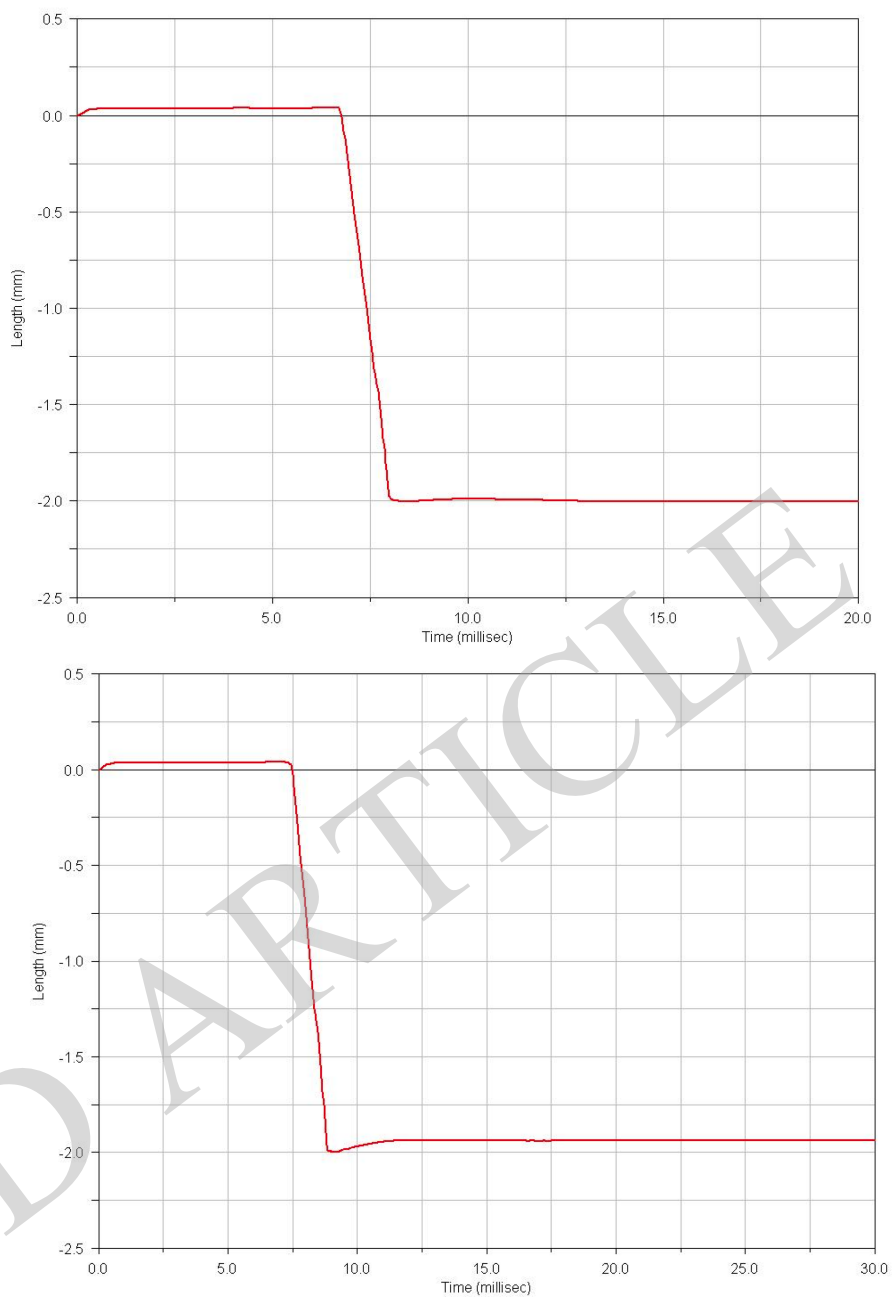

\subsection{Suction}

With anti force must ensure that any phase, action value when the suction characteristics of reaction force in the air gap is larger than the minimum, or the electromagnetic contactor cannot reliably pull. In the harmonic excitation, closing phase angle of 60 degrees, very obvious anti force is larger than the suction value, so in the power supply for containing harmonic component of the excitation source, can not guarantee the electromagnetic contactor can work stably.

\section{CONFLICT OF INTEREST}

The authors confirm that this article content has no conflict of interest.

\section{ACKNOWLEDGEMENTS}

Declared none.

\section{REFERENCES}

[1] Mark A. Juds, John R. Brauer. AC contactor motion computed with coupled electromagnetic and structural finite elements. IEEE Transactions on Magnetics, 2011, 31:p3575-3577 
[2] R. Gollee, G. Gerlach. An FEM-based method for analysis of the dynamic behavior of AC contactors. IEEE Transactions on Magnetics, 2010, 36: p1337-1340

[3] Mur G (Delft Univ of Technology). Finite-element modeling of electromagnetic fields. Proceedings of the 1996 3rd International Conference on Software for Electrical Engineering Analysis and Design ELECTROSOFT'96, 2000, p177-186

[4] Gollee R. (Dresden Univ of Technology). FEM-based method for analysis of the dynamic behavior of AC contactors. IEEE Transactions on Magnetics, v 36, n 41, Jul, 2013, p1337-1340

[5] Kawase, Yoshihiro (Gifu Univ). 3-D finite element analysis of operating characteristics of $\mathrm{AC}$ electromagnetic contactors. IEEE Transactions on Magnetics, 1994, p3244-3247

[6] Djokic, Sasa Z. Sensitivity of AC coil contactors to voltage sags, short interruptions, and under voltage transients. IEEE Transactions on Power Delivery, v19, n3, July,2012, p1299-1307

[7] Wada, Masayoshi (Fuji Elec. Corp. Res. and Devmt. Ltd). Dynamic analysis and simulation of electromagnetic contactors with AC solenoids. IECON Proceedings (Industrial Electronics Conference), v4, 2012, p2745-2751

[8] Wenxiong Li, Jianguo Lu, Hui Guo et al. AC Contactor Making Speed Measuring and Theoretical Analysis. Proceedings of the 50th IEEE Holm Conference on Electrical Contacts and the 22nd International Conference on Electrical Contacts, 2004, 403-407

[9] Li Xingwen, Chen Degui, Li Zhipeng, etc. Numerical analysis and experimental investigation of dynamic of $\mathrm{AC}$ contactors concerning with the bounce of contact. IEICE Transactions on Electronic, 2013, 8: 1318-1323

[10] Kiely J.H., Nouri H., Kalvelage F., Davies T.S.. Development of an application specific integrated circuit for reduction of contact bounce in three contactors. Electrical Contacts, Proceedings of the Annual Holm Conference on Electrical Contacts, 2010, 120-I29

[11] Hoidalen H K, Runde M, "Continuous monitoring of circuit breakers using vibration analysis". IEEE Transactions on Power Delivery, 2005, 20(4): pp.2458-2465.

[12] Landry M, Lonard F, Beauchemin R, "An improved vibration analysis algorithm as a diagnostic tool for detecting mechanical anomalies on power circuit breakers". IEEE Transactions on Power delivery, 2008, 23(4): pp.1986-1994.

[13] Huang J, Hu X G GENG X, "An intelligent fault diagnosis method of high voltage circuit breaker base on improved EMD energy entropy and multi-class support vector machine". Electrical Power System Research, 2011, 81(2): pp.400-40

(C) Yufeng and Lufeng; Licensee Bentham Open.

This is an open access article licensed under the terms of the Creative Commons Attribution Non-Commercial License (http://creativecommons.org/licenses/by-nc/3.0/) which permits unrestricted, non-commercial use, distribution and reproduction in any medium, provided the work is properly cited. 